\title{
Lo fantástico más allá de la vacilación: la representación mimética del miedo en dos cuentos de Bioy Casares y Cortázar
}

Andreas Kurz Universidad de Guanajuato

\section{Resumen}

El artículo revisa algunos conceptos y definiciones de lo fantástico literario y pretende diferenciarlo de lo postulado por el realismo mágico y lo real maravilloso. Se proponen como textos clave al respecto: el libro de Franz Roh que da nombre al realismo mágico, la historia de la literatura fantástica, por H. P. Lovecraft; así como la tesis de 'das Unheimliche', de S. Freud. A manera de hipótesis, establecemos el carácter mimético de la literatura fantástica que representa el miedo, en oposición a la idea de vacilación expuesta por Todorov. Finalmente, pretendemos testar nuestra hipótesis mediante el análisis de dos cuentos canónicos escritos por Bioy Casares y Cortázar.

Palabras clave: literatura fantástica, realismo mágico, real maravilloso, Bioy Casares, Cortázar.

\section{Abstract}

This article explains some concepts and definitions of fantastic literature and tries to separate them from 'realismo mágico' and 'lo real maravilloso'. Franz Roh's book, H. P. Lovecraft's history of fantastic literature and Freud's concept of the 'unheimlich' are used as key texts to reach this aim. Our principal hypothesis states the mimetic charac- 
ter and the representation of fear as the main ingredients of fantastic literature, opposing the idea of vacillation exposed by Todorov. We try to test our hypothesis in the analysis of two canonical short stories by Bioy Casares and Cortázar.

Keywords: fantastic literature, realismo mágico, real maravilloso, Bioy Casares, Cortázar.

Cuando Alejo Carpentier publica, en 1949, El reino de este mundo, es un novelista casi novato. Había escrito, más de 20 años antes, Écue-Yamba-O, su relato afrocubano, del que se distanciaría posteriormente y calificaría como texto malogrado: "Esta primera novela mía es tal vez un intento fallido por el abuso de metáforas, de símiles mecánicos, de imágenes de un aborrecible mal gusto futurista y por esa falsa concepción de lo nacional que teníamos entonces los hombres de mi generación” (1975: 63). Además, Carpentier era autor de algunos cuentos, crónicas y de La música en Cuba (1946). De ninguna manera era previsible el impacto que tendría la novela de 1949, pero más que la novela misma: las escasas seis páginas de su prólogo. La idea de lo real maravilloso proclamada por el escritor cubano-francés en este corto texto se convertiría en uno de los conceptos más populares, comentados y manipulados de la narrativa hispanoamericana de la segunda mitad del siglo XX. ${ }^{1}$ Lo real maravilloso compitió (y compite), por un lado, con el concepto del realismo mágico, que se limita a ciertos aspectos de las letras latinoamericanas del siglo XX; por otro lado, con el de lo fantástico, que abarca la literatura universal de varios siglos. ${ }^{2}$ A la postre, sin embargo, y probablemen-

${ }^{1}$ Novela y prólogo aún sirven como base e inicio de la nueva novela histórica ideada por Seymour Menton en 1993.

${ }^{2}$ En la crítica hispanoamericana que se ocupa de la literatura fantástica, Raúl Calderón Bird, en una tesis no publicada, subraya el carácter universal, atem- 
te a raíz de un fenómeno que podría describirse como el intento desesperado por parte de la crítica literaria de encontrar y manejar definiciones inequívocas, resulta casi imposible diferenciar los tres conceptos entre sí.

En 1997, Alicia Llorena publicó "Un balance crítico: la polémica del realismo mágico y lo real maravilloso americano (19551993)". Este resumen de la polémica sigue vigente 20 ańos después. En nuestro contexto importa resaltar sobre todo un resultado de Llorena: la casi siempre inadecuada inserción de lo fantástico en la polémica, específicamente la subordinación de realismo mágico y lo real maravilloso a diversas concepciones de lo fantástico (Llorena, 1997: 108s.). Ya antes, Irlemar Chiampi había insistido en este aspecto. La investigadora brasileña opera con el concepto de una "verosimilización" de lo inusitado y milagroso que diferencia el realismo mágico y lo real maravilloso de lo fantástico. Para evitar más confusiones conceptuales aboga a favor del término "realismo maravilloso". ${ }^{3}$ Resulta, entonces, inevitable remitir una vez más al texto fundacional de lo real maravilloso.

Carpentier presupone "una fe" para "la sensación de lo maravilloso" (1987: 15). En otras palabras: el milagro y lo fantástico

poral y transversal del género. Lo cito, dado que pocos críticos insisten en este factor simple, pero fundamental: "Lo fantástico no implica una cosmovisión colectiva, ni se refiere a escuela, movimiento o época artística alguna, sino más bien a una suerte de narración antinómica y transhistórica que se cruza con la visión de mundo y las peculiaridades de cada escuela y estilo" (2002: 136). De manera similar argumenta Rodrigo Pardo Fernández: "La literatura fantástica ha constituido una constante, una necesidad de todas las culturas" (2009: 11). Sin embargo, Pardo Fernández deduce de este hecho la inutilidad de proponer teorías y clasificaciones de lo fantástico (14), es decir, aboga por una postura relativista poco productiva. Tal relativismo se nota en estudios como los de Carlos Abraham (2006) que emplean de manera indistinta los términos: novela gótica, ciencia ficción y literatura fantástica.

${ }^{3}$ Remito a Irlemar Chiampi, El realismo maravilloso. Forma e ideología en la novela hispanoamericana, (1983). 
no se perciben como tales, sino como hechos naturales y cotidianos: "Los que no creen en santos no pueden curarse con milagros de santos, ni los que no son Quijotes pueden meterse, en cuerpo, alma y bienes, en el mundo de Amadis de Gaula o Tirante el Blanco" (1987: 15). El novelista prescinde deliberadamente de un componente básico del juego literario: el lector. El que lee sobre milagros y hechos fantásticos no necesariamente cree en milagros. Al contrario: puede percibir lo leído como milagroso y fantástico, a final de cuentas como ficción, como mentira.

En su no siempre verdadera Historia verdadera del realismo mágico, Seymour Menton califica "la fe que no exige pruebas" como elemento distintivo de lo real maravilloso y lo fusiona con el realismo mágico: "los fenómenos en las obras mágicorrealistas que yo he llamado asombrosos pueden no parecerlo desde una perspectiva distinta de la occidental o falogocéntrica" (1998: 163). ${ }^{4}$ El amigo de García Márquez comete el mismo error que Carpentier, ignora la existencia de los lectores reales. Éstos, aunque su objetivo principal sea la evasión, saben que leen un texto ficticio; por lo tanto, no necesitan de "una fe" para poder aceptar los hechos maravillosos o fantásticos narrados, sólo necesitan del "como si" literario, del pacto ficticio con el narrador. Es improbable que novelas como $E l$ reino de este mundo o Cien años de soledad encuentren lectores que vivan en un mundo real maravilloso. Si los hubiera, por otro lado, tendrían que percibir estas novelas como realistas y posiblemente se aburrirían con tanta reproducción de lo conocido.

Carpentier, desde la posición del creador, y Menton, desde la del crítico, procuran definir lo indefinible y quedan atrapados en una paradoja. Ningún texto literario puede ser, por razones lógicas, ni mágicorrealista ni real maravilloso. Los actos descritos quizás sí lo pueden ser, pero sólo desde la perspectiva de un lector

${ }^{4}$ Menton toma la expresión "la fe que no exige pruebas" de un artículo de la crítica Biruté Ciplijauskaité. 
con una percepción muy distinta a la "occidental o falogocéntrica". Este lector, sin embargo, sería u otra ficción o una construcción de crítica y teoría literarias, sería un lector implícito o ideal o privilegiado, un lector que la estética de la recepción necesita para reconstruir diferentes sistemas de lecturas de un texto literario, pero que no sirve como comprobante de la existencia de textos mágicorrealistas o real maravillosos. Un círculo vicioso. El carácter universal de lo fantástico — un concepto adoptado por (no surgido en) la literatura latinoamericana- podría ofrecer la posibilidad de romper este círculo vicioso, podría unir lo real maravilloso y el realismo mágico en un modelo descriptivo que abarque sectores amplios de la literatura latinoamericana de los últimos 200 años. ${ }^{5}$ Sin embargo, la legítima e inevitable pregunta de ¿qué es lo fantástico? impide esta unificación, dado que forma cánones específicos limitados a los autores que confirman la definición aplicada por el crítico canonizador. Estamos atrapados en una red de teorías que mediante hechos encontrados en textos ficticios se explican a sí mismas. ${ }^{6}$ Algunas de estas teorías que pretenden explicar y definir lo fantástico se discutirán en este artículo, discutirlas todas se ha vuelto imposible.

La variedad (¿confusión?) terminológica entre realismo mágico, lo real maravilloso y literatura fantástica sigue constituyendo, aún después de los trabajos de Chiampi y Llarena, uno de los temas predilectos de la crítica que, en y fuera de América Latina,

${ }^{5}$ Son raros los estudios que se ocupan de la literatura fantástica latinoamericana del siglo XIX. Remito sobre todo a Oscar Hahn, El cuento fantástico hispanoamericano en el siglo XIX (1978).

${ }^{6}$ Una discusión detallada de tales teorías se encuentra en numerosos textos de Karl Popper. Remito especialmente a Conjeturas y refutaciones (1967) y Búsqueda sin término (1977), la "autobiografía intelectual" del filósofo austriaco. Popper aduce una y otra vez las teorías marxista y psicoanalítica como representantes de teorías "ad hoc" (es decir: auto-explicativas). La mayoría de las teorías literarias creadas en el siglo XX debería incluirse en esta categoría. 
se ocupa de la literatura hispanoamericana. No dudo de la necesidad y utilidad de una terminología especializada en las ciencias literarias (y en cualquier otra ciencia). Sin embargo, una especie de navaja de Occam podría ser — quizás - de provecho para la discusión alrededor de los términos mencionados. Propongo dos textos que podrían servir como navaja: el libro de Franz Roh que es prestanombre del realismo mágico, ${ }^{7}$ y El horror sobrenatural en la literatura de H. P. Lovecraft. Procuraré demostrar, finalmente, que la teoría de lo fantástico de Todorov pertenece, a pesar de su gran valor intrínseco, al grupo de las teorías auto-explicativas, dado que excluye cierto número de textos que el sentido común en su versión popperiana ${ }^{8}$ clasificaría como fantásticos. El estudio de Freud sobre lo "siniestro", por otro lado, cobra validez si se extraen de él las posibilidades de la palabra unheimlich. A manera de prueba, aplicaré los resultados extraídos del análisis mencionado a dos cuentos antológicos de la narrativa hispanoamericana del siglo XX:9 "El calamar opta por su tinta", de Adolfo Bioy Casares, y "Las Ménades", de Julio Cortázar.

${ }^{7}$ Menton discute las tesis de Roh sobre todo en el apéndice de su Historia verdadera (1998: 209ss).

${ }^{8}$ Cualquier conocimiento, según Popper, parte del sentido común, la ciencia entera se construye sobre él. Popper está consciente de lo inestable del sentido común. Sin embargo, el sistema científico que se erige sobre él no es menos inestable, dado que no existe ningún conocimiento que sea absolutamente seguro. El único conocimiento posible es el "sentido común ilustrado", es decir, el conocimiento que parte del y regresa al sentido común. $C f$. sobre todo el $C o$ nocimiento objetivo (1974: 50ss). La terminología literaria no parte del sentido común, ya que no corresponde a ningún fenómeno que éste pueda percibir y formular, sino que apenas construye los fenómenos que después la crítica observa y explica. De ahí la variedad y confusión reinantes en la ciencia literaria que marcan al mismo tiempo sus limitantes y sus posibilidades de desarrollo.

${ }^{9}$ Evito en este caso el epíteto "fantástico" precisamente porque la pertenencia de los dos cuentos tratados al género es discutible según la definición y la teoría aceptadas. 
Nach-Expressionismus. Magischer Realismus fue publicado en 1925. En el prólogo, Franz Roh subraya la irrelevancia del término realismo mágico:

No concedemos mucha importancia al título de 'realismo mágico'. Dado que el hijo necesitaba un nombre verdadero y 'post-expresionismo' sólo asignaba su procedencia y ubicación temporal, agregamos este segundo, mucho después de terminar el libro. Nos pareció más adecuado que 'realismo ideal' o 'verismo' y 'neoclasicismo', los que sólo representan una parte del movimiento. (Roh: s.p.; la traducción es mía).

Por razones inciertas, la traducción española de 1927 invirtió el título: Realismo mágico, post expresionismo. Sin este cambio la obra de García Márquez se conocería hoy posiblemente como post expresionista.

Roh analiza tendencias nuevas reconocibles en la pintura europea a partir de 1920 que se alejan de la abstracción expresionista y vuelven a confiar en las posibilidades miméticas de las artes plásticas: "El post-expresionismo intenta re-instaurar la realidad en el contexto de su visibilidad. La alegría elemental del reconocimiento vuelve a ser parte del juego" (Roh, 1925: 27). Sin embargo, no se trata de neo-realismo, sino más bien de la representación de mundos interiores con la ayuda de la realidad tangible. Un "mundo posible" es su tema, las tensiones entre la idea y la realidad (71s). Las hipótesis de Roh se insertan en el dualismo entre arte barroco y arte clásico propagado, entre otros, por Heinrich Wölfflin. Barroco se relaciona, en este contexto, con movimiento y dinamismo; clá- 
sico con lo estático y establecido (116s). ${ }^{10}$ El post-expresionismo, un movimiento clásico, reacciona contra las exageraciones barrocas del expresionismo (84s). Roh detecta un desarrollo parecido en la música y la literatura de la época, mas, por razones obvias, limita sus análisis a la escena artística europea (109), excluye — también por razones obvias - posibles tendencias paralelas fuera del viejo continente. Sin embargo, no es difícil hallar similitudes entre el desarrollo pictórico descrito por Roh y el rumbo tomado por parte de la narrativa hispanoamericana a partir de 1950, aproximadamente.

El realismo mágico, la literatura fantástica y las técnicas de lo real maravilloso podrían interpretarse como tendencias miméticas, pero no estrictamente realistas. Es decir: no es el temario el generador de lo fantástico, sino la técnica narrativa (que no debe confundirse con el estilo). Carpentier se autodefine y define a los autores más influyentes de la literatura iberoamericana como barrocos. El estilo puede ser barroco o parco ("clásico"); la actitud narrativa, no obstante, es mimética: el fenómeno literario mismo genera hechos insólitos o mundos enteros fuera de lo común que la narrativa copia. El narrador es, en esta constelación, un contador de historias con una dicción que es, a pesar de lo barroco del estilo, básicamente oral. ${ }^{11}$ Es igualmente razonable diferenciar las tendencias de corrientes orientadas hacia la novela posmoderna o el nouveau roman francés, cuyos representantes más destacados, en México, se encuentran en el grupo del medio siglo: Salvador Elizondo, Sergio Pitol, Juan García Ponce, etc. Las diferenciaciones entre barroco

${ }^{10}$ El catalán Eugenio d'Ors resume en su pequeño e influyente libro Lo barroco esta dicotomía y la extiende a campos ajenos al arte. El descubrimiento de la circulación sanguínea sería, según d'Ors, una innovación genuinamente barroca. ${ }^{11}$ Cabe agregar que no se trata de literatura oral. Walter Ong, cuyo Orality and Literacy sigue siendo el estudio canónico sobre cuestiones de oralidad, demostró convincentemente que el término "literatura oral" es un oxímoron. Se trata, repito, de una actitud oral inserta en un contexto altamente literarizado. 
y clásico y entre dinámico y estático son, por supuesto, arbitrarias; podrían ser sustituidas por otros pares. Sin embargo, el hecho descrito no cambia a raíz de un cambio terminológico. La literatura fantástica hispanoamericana sería entonces, más allá de sus manifestaciones heterogéneas concretas, una corriente mimética opuesta a corrientes que cuestionan valor y funcionamiento de la mimesis.

H. P. Lovecraft publica Supernatural Horror in Literature (El horror sobrenatural en la literatura) en 1927. El libro es, en primer lugar, una historia comprimida de la literatura fantástica, sobre todo de sus exponentes ingleses, norteamericanos, alemanes y franceses; sin embargo, las páginas introductorias del ensayo contienen una teoría del género en ciernes.

Lovecraft construye su teoría sobre dos ingredientes básicos: el mito y el "temor cósmico". El escritor estadounidense se apoya en una idea relativamente gastada de las funciones del mito: un relato que explica fenómenos misteriosos y amenazantes; un relato que, por ende, forma el inicio de cualquier literatura (1995: 8ss). ${ }^{12}$ Las historias fantásticas elaboradas a raíz del mito se convierten de este modo en "nuestra única salvaguardia en contra de los asaltos del caos y de los demonios del espacio insondable" (11).

${ }^{12}$ Puede ser que la idea sea gastada, sin embargo, se repite una y otra vez hasta nuestras fechas en textos que pretenden explicar el origen de la literatura. Mario Vargas Llosa, en una conferencia presentada el 27 de agosto de 2007 en Salzburgo, ve en el relato mítico no sólo el origen de la literatura, sino también el momento de humanización de la especie. Sobre todo Joseph Campbell y Mircea Eliade han demostrado en numerosos textos que el mito y el relato mítico no forman mundos paralelos, sino, al contrario, construyen el mundo tangible, es decir, cumplen con funciones no literarias, no ficticias. 
Resulta más esclarecedor el "temor cósmico", expresión genuinamente lovecraftiana, que origina la producción de relatos míticos. "El terror cósmico", escribe, "figura como un ingrediente del primitivo folklore de todas las razas, y cristalizó en las más antiguas baladas, crónicas y escrituras sagradas" (13). Autores anónimos en un inicio, escritores profesionales después se aprovechan de este sentimiento universal y atemporal para forjar las historias fantásticas cuya función deja de ser la del relato mítico y gana objetivos puramente estéticos, propiamente dicho literarios, sin perder, no obstante, ciertas nociones religiosas y protectoras que, paradójicamente, garantizan "la potencia de unos horrores a mitad explicados y a mitad insinuados" (14). ${ }^{13}$

$\mathrm{Si}$ adaptamos estas ideas a la narrativa hispanoamericana del siglo XX, podemos establecer el miedo y la duda existencial como motores de su vertiente fantástica. Miedo y duda ante fenómenos desconocidos o intangibles, miedo y duda ante la irracionalidad, la irrupción de lo objetivamente inexplicable, miedo y duda ante los abismos de la propia personalidad. El omnipresente "temor cósmico" de Lovecraft se bifurca varias veces hasta abarcar las esferas social, política, psicológica, etc. Este miedo no es tema exclusivo de la literatura fantástica, de la rama mimética de la narrativa iberoamericana, es, al contrario, un tema universal. De nuevo hay que recurrir a la actitud narrativa que genera lo genuinamente fantástico del miedo. Éste se exterioriza, se cosifica, eventualmente se exorciza: el miedo como prosopopeya de lo fantástico. Algo invisible puede generar el miedo — como en "L'Horla", el cuento clásico de Maupassant—, mas la narración procura ser su mimesis.

En este contexto me permito oponerme a Lidia Morales Benito que, en un artículo reciente que retoma la teoría de lo neofantástico de Jaime Alazraki, afirma que los relatos fantásticos hispanoa-

${ }^{13}$ Lovecraft se refiere en este pasaje sobre todo a la literatura fantástica producida en la Germania medieval. 
mericanos de Cortázar y Bioy sustituyen los monstruos y vampiros de los relatos clásicos de Poe y Maupassant por sujetos y objetos concretos y tangibles (2011: 133). Morales Benito no toma en cuenta que precisamente Poe y Maupassant pretenden representar el poder del miedo sobre individuos concretos sin recurrir a su exteriorización con la ayuda de monstruos y vampiros. Son ellos los posibles predecesores de la actitud mimética "post-expresionista" de la literatura fantástica moderna en América latina.

El mismo Alazraki raras veces remite a precursores de la tendencia neofantástica; parece, al contrario, asumirla como la genuina aportación latinoamericana a la literatura fantástica universal. A partir de los ańos 60, Alazraki desarrolla el concepto en primera instancia en el contexto de la búsqueda de un nuevo lenguaje literario que pueda sustituir las exageraciones formales de los modernistas en todo el continente latinoamericano. En "Borges y el problema del estilo" (1967), reconstruye el camino de un Borges "preciosista", aún presente en las primeras Inquisiciones, hacia un Borges clásico, puro y realista. Clasicismo, pureza y realismo son, sin embargo, criterios lingüísticos, de ninguna manera semánticos. Borges diferencia — así Alazraki- entre el "énfasis" de los románticos, los que querían crear la realidad mediante el lenguaje, y la mimesis de los clásicos. Él mismo se percibe como clásico (Alazraki, 1967: 210s). El estilo no es ornato, sino función (211): así resume el crítico el cambio de posturas de Borges. ${ }^{14}$ El narrador argentino escribe sus cuentos fantásticos precisamente con este

${ }^{14}$ En "El texto como palimpsesto: lectura intertextual de Borges" (1984), Alazraki inserta el desarrollo descrito 17 años antes en las teorías de la intertextualidad, sobre todo en las formuladas por Genette. Los cuentos fantásticos de Borges son palimpsestos en diferentes grados, su literatura toda es intertextualidad avant la lettre (283). Libros que reproducen libros, textos que imitan, caricaturizan o prolongan otros textos: de nuevo se evidencia una actitud mimética cuyo objeto es, en este caso, la literatura misma. 
lenguaje parco, pulido, sin ornamentación. ${ }^{15} \mathrm{Su}$ actitud literaria es evidentemente mimética. El cuento reproduce realidades: si estas realidades pertenecen al mundo objetivo, al onírico o al mundo interno de los personajes es secundario. El miedo, la duda y la inseguridad ontológica forman parte de estos mundos, son los verdaderos objetos de la mimesis practicada por Borges. ${ }^{16}$

Lo neofantástico de Jaime Alazraki parece confirmar el miedo y la mimesis como elementos constituyentes de la narrativa fantástica hispanoamericana del siglo XX. Sin embargo, hay derivaciones de su teoría que, una vez más, se acercan al terreno de las teorías "ad hoc". En su reseña de Hacia Cortázar, Luis Parkinson Zamora interpreta lo neofantástico como la apertura del género hacia el mundo que se manifiesta sobre todo en Cortázar (1998: 180). Borges, cuyo mundo literario se encierra en sí mismo mediante la autorreferencialidad y el palimpsesto, no pertenecería, entonces, a la literatura fantástica. No creo que esto agrade a Alazraki. Una nueva teoría de lo fantástico, muy amplia y hospitalaria a primera vista, empieza a formar su propio canon según los postulados de la teoría y de sus exégesis. Carlos Yushimito del Valle, por otro lado, insiste en una metáfora que se explica a sí misma como núcleo de lo neofantástico (2009: internet), es decir: no tiene sentido tratar de explicar las metáforas de los cuentos fantásticos, son autorreferenciales, no significan nada, "sólo" son. ${ }^{17}$ Esta interpretación

${ }^{15}$ Muy probablemente se trata de una herencia directa de Kafka.

${ }^{16} \mathrm{El}$ proceso que lleva de la novela naturalista francesa a la novela decadentista es análogo. Cuando Joris Karl Huysmans publica $\grave{A}$ rebours, Zola tacha a su alumno más fiel como traidor. Sin embargo, Huysmans "sólo" dio un paso lógico en el desarrollo del naturalismo: de la representación de mundos externos a la de mundos internos igualmente abismales y - muchas veces- abominables. ${ }^{17}$ Los ruidos de "Casa tomada" pueden ser cualquier cosa, así como el delito de Josef K. en El proceso puede ser cualquier cosa. Lo único que cuenta es la amenaza representada en ambos textos, el miedo reproducido miméticamente a través de una metáfora autónoma. 
de lo neofantástico vuelve a incluir los mundos literarios herméticos de Borges...

\section{III}

Los dos elementos constituyentes centrales de los textos fantásticos que podemos aislar en los libros de Roh y Lovecraft —y que lo neofantástico de Jaime Alazraki hasta cierto grado confirma— son, por ende, su carácter mimético y el miedo como impulsor de la narración que, mediante un movimiento recursivo, remite al principio mimético. Insisto en que el miedo impulsa y genera la narración. Sin embargo, al mismo tiempo constituye su tema decisivo.

Este binomio sencillo ha sido aceptado por Adolfo Bioy Casares en el prólogo a la Antología de la literatura fantástica. Desde la primera oración del texto, el confidente de Borges no procura esconder su deuda con Lovecraft: "Viejas como el miedo, las ficciones fantásticas son anteriores a las letras. Los aparecidos pueblan todas las literaturas: están en el Zendavesta, en la Biblia, en Homero, en Las Mil y una Noches" (2008: 7). ${ }^{18}$ Bioy Casares no discute cuestiones estilísticas, tampoco pretende delimitar el género según sus tópicos y contenidos. Aunque elabora una lista de doce temas fantásticos, acepta que se trata de un género en continuo movimiento: "Pedimos leyes para el cuento fantástico; pero ya veremos que no hay un tipo, sino muchos, de cuentos fantásticos" (8). Es imposible trazar los límites exactos de la literatura fantástica. Bioy Casares - y con él muy probablemente Borges — la reduce al miedo y a la mimesis, a la eficaz sorpresa del argumento (9), reproduce en otras palabras las hipótesis centrales de Roh y Lovecraft.

"El calamar opta por su tinta", uno de los cuentos más conocidos de Bioy, puede ilustrar el procedimiento. Un extraterrestre

${ }^{18}$ El prólogo data de 1940. 
irrumpe en la atmósfera calmada, un tanto folclórica y pintoresca de un pueblo de la provincia argentina. "Más ocurrió en este pueblo en los últimos días que en el resto de su historia”, así comienza el relato (1999: 211). Desde sus inicios, la narración se ubica en un contexto historicista, es decir, eminentemente mimético. El narrador, maestro de escuela, es, al mismo tiempo, cronista del pueblo. Los acontecimientos se presentan como históricos, a final de cuentas como verídicos. El narrador incluso recurre al cuestionamiento de un testigo ocular, procedimiento clásico en la búsqueda de verdad. Sin embargo, este testigo, el simpático, pero intelectualmente limitado Don Tadeíto, es poco confiable. El maestro y sus compańeros de tertulia se enteran de la presencia en el pueblo de un extraterrestre con forma de calamar y una necesidad vital de agua, se enteran hasta de su objetivo - salvar el mundo de un probable cataclismo nuclear-, mas nunca lo ven. Los únicos que sí podrían confirmar la verdad de su presencia son el respetable Don Camargo, una pura referencia en la narración, y — de nuevo- Tadeíto quien da la noticia del fallecimiento de la criatura: "El bagre se murió”, así sus palabras lacónicas que, por supuesto, no aclaran nada (224).

Bioy Casares recurre a técnicas narrativas realistas, inclusive parodia las posturas del costumbrismo literario para describir una criatura que puede o no existir, que puede o no ser un extraterrestre. La actitud mimética del cuento es evidente, mas ¿qué "se copia”? El miedo y las dudas del narrador en primer lugar, de sus co-tertulios en seguida. Se les revela la propia insignificancia y pequeñez, su estulticia e impotencia ante fenómenos fuera del alcance de sus facultades comprensivas, la muerte cuya fatal atracción evoca el librero Villarroel con las palabras aparentemente paródicas, pero profundamente angustiosas: "Como de ninguna manera nadie escapará a la muerte, ¡que venga pronto, para todos, que así la suma del dolor será la mínima!” (223). Se copia también 
el miedo de entrar a la historia, miedo colectivo y social. Pocos lectores ubicarían en una primera recepción la trama del cuento a mediados del siglo XX. El pueblo argentino aparece como lugar estancado en el tiempo: en el siglo XIX, quizás a comienzos del $\mathrm{XX}$. Apenas la sorprendente mención de la bomba atómica ubica al lector. Con su decisión de ignorar la existencia de algo nuevo en el pueblo, sus habitantes se niegan a formar parte de la historia, no aceptan su propia dependencia de procesos históricos. Nadie les podría reprochar esta actitud, sólo el narrador — hombre de letras, "intelectual" no en balde, es decir: individuo que debería asimilar su responsabilidad histórica - se presenta en el cuento vagamente culpable.

Bioy Casares, entonces, elabora un cuento fantástico a primera vista irónico y paródico que, a segunda vista, revela mediante una narración claramente mimética un mundo escondido de miedos y dudas ontológicas, tanto a nivel individual como colectivo y social.

Es lícito calificar "El calamar opta por su tinta" como una pequeña obra maestra del género fantástico. Sin embargo, si aplicáramos los criterios establecidos por Tzvetan Todorov en su justamente famosa y explotada Introducción a la literatura fantástica, entonces el cuento de Bioy ni siquiera pertenecería al género. El mismo Todorov prevé esta problemática. Para definir un género no es necesario —además sería imposible- conocer a todos sus representantes. Hay que reducir el objeto de estudio a un corpus de textos manejable que pretende representar lo arquetípico del género. Esta inevitable reducción inicial, que por inevitable no deja de ser aleatoria, aumenta la probabilidad de que un texto "nuevo" cambie el género, que sea necesario modificar o abandonar del todo los criterios propuestos originalmente para la definición del género. Parafraseo a Todorov: un texto nuevo sí puede modificar el género literario; un tigre nuevo nunca modificará su género (1994: 9). Es decir: género literario y género biológico no han de confundirse. 
El primero se expone a cambios continuos que dificultan (probablemente imposibilitan) su descripción; el segundo es relativamente estable y permite una descripción segura. ${ }^{19}$

Me concentro en sólo uno de los rasgos definitorios que propone el gran crítico búlgaro, posiblemente el más potente: la vaguedad. Todorov sitúa lo fantástico entre cuatro categorías bien delimitadas: extraño puro, fantástico-extraño, fantástico-maravilloso y maravilloso puro. “(L)o fantástico puro”, explica, "estaría representado por la línea media que separa lo fantástico-extraño de lo fantásticomaravilloso; esta línea corresponde a la naturaleza de lo fantástico, frontera entre dos territorios vecinos" (39). Frontera significa, en este contexto, el vacilar entre creer y no creer, tanto del narrador como del lector implícitos. Lo verosímil puede ser fantástico (41), lo sobrenatural e increíble pueden serlo, si dejan abierta o la puerta de una explicación racional o la de un simple acto de fe. Lo que se presenta como inexplicable y sobrenatural, como monstruoso e irracional sin más no podría ser fantástico.

Todorov establece el momento de duda en el lector implícito, nunca en el real, respecto a la credibilidad de lo narrado como momento decisivo que genera la literatura fantástica. En "El calamar opta por su tinta” no existe este momento de vacilación. La narración mimética tiene como referente primario los miedos, inseguridades y angustias de los protagonistas, el narrador incluido, de cuya veracidad no cabe dudar. El extraterrestre-calamar es un referente subordinado, no mucho más que un catalizador, una metáfora dentro de otra metáfora que subraya, paradójicamente,

${ }^{19}$ Cabe mencionar que lo expuesto por Todorov asimila las propuestas de Karl Popper para la formulación de teorías científicas cuya validez se mide con el parámetro de su falseabilidad mediante pruebas estrictas. Es decir: un hecho nuevo cambia la teoría que es, en este sentido, mucho más un género literario, que uno biológico. Todorov integra The Logic of Scientific Discovery en su bibliografía. No obstante, la teoría finalmente expuesta por el crítico asume, por lo menos en los ojos de muchos de sus lectores y exégetas, el rango de infalibilidad. 
la realidad de los miedos aludidos. El criterio de la vaguedad, por ende, no opera en el cuento de Bioy. Es posible, por supuesto, eliminar la obra del canon de lo fantástico. No obstante, el sentido común popperiano sí la percibe como fantástica. ${ }^{20}$ Es preferible, entonces, modificar levemente la teoría de Todorov, aplicar la navaja de Occam que proporcionan Roh y Lovecraft. ${ }^{21}$

La estética de la recepción, que Todorov conoce bien desde que ésta se iniciara en la Universidad de Constanza, podría aportar un estudio valioso acerca de las reacciones concretas de lectores concretos de literatura fantástica. ¿En qué momento vacilan? ¿Por qué? ¿En qué momento termina la duda para convertirse en certeza? ¿Cómo decepciona y corrige la literatura fantástica el horizonte de expectativas de sus lectores? Sin embargo, la praxis de la crítica literaria se enfrenta en estos casos a un problema fundamental: la falta de documentación fiable. Es decir, ni siquiera encuestas amplias entre lectores modernos son capaces (por razones estadísticas y psicológicas) de representar las reacciones auténticas de un grupo de lectores. ${ }^{22}$ La vacilación, por ende, se vuelve un criterio vago que sólo la lectura del crítico establece y confirma (esto es: una lectura específica, quizás privilegiada, entre millones de reacciones lectoras

${ }^{20}$ Véase la nota 8.

${ }^{21}$ Todorov cita a Lovecraft, pero rechaza sus posiciones, dado que el norteamericano argumenta desde la perspectiva de un lector real (1994: 31). Podemos oponer a esta crítica, en sí acertada, que el "temor cósmico", principal ingrediente fantástico de Lovecraft, afecta a autores, narradores y lectores reales e implícitos con la misma intensidad.

${ }^{22}$ Mucho menos es posible determinar las reacciones de lectores en diferentes momentos históricos y regidos por contextos sociales divergentes ante uno y el mismo texto. Véase para este tema sobre todo la antología En busca del texto. Teoría de la recepción literaria (2008), recopilada por Dietrich Rall. En ella especialmente "Para una historia literaria del lector", de Harald Weinrich, e "Investigación de las influencias y de la recepción”, de Maria Moog-Grünewald. 
posibles), pero que no podría ser el elemento que caracteriza todo el género.

Jean-Luc Steinmetz, en un estudio de 1990, se da cuenta de que la vacilación implica otra dificultad: se trata de un momento y los momentos no suelen ser ni tangibles ni medibles. Con menos razón aún un momento debería ser el rasgo fundamental de un género literario. Escribe Steinmetz:

La définition de Todorov, qui se fonde, en fait, sur un certain type de réaction psychique, a le tort de limiter le fantastique à un très court temps d'hésitation, alors même que les écrits de ce genre obéissent à une longue préparation, une mise en condition du lecteur et ménagent une climax, une progression ascendante [...]. Dès lors et par purisme, faudrait-il distinguer la réaction vive (et brève) de la composition méditée et longuement développée? (1990: 14).

Las hipótesis de Todorov, en otras palabras, reducen la literatura fantástica a un efecto que quizás ha sido calculado por el autor, pero de ninguna manera hace justicia a un género de construcción artística compleja. ${ }^{23}$ Precisamente esta reducción impide, en la teo-

${ }^{23}$ Steinmetz critica igualmente los postulados de los teóricos clásicos de lo fantástico: Pierre-Georges Castex y Roger Caillois. Rechaza sobre todo su concentración en los aspectos temáticos del género (1990: 10ss). Sin embargo, los postulados de Steinmetz no difieren mucho de los catálogos temáticos ofrecidos por Castex, Caillois y también Todorov: los amplía y categoriza, pero no propone criterios diferentes. Me permito, en este contexto, remitir a Louis Vax quien, en L'art et la littérature fantastique (1960), subordina su catálogo de temas a una función: la introducción del miedo en la diégesis: "Lart fantastique doit introduire des terreurs imaginaires au sein du monde réel" (Vax, 1960: 6). Sin embargo, insisto en que los miedos y el terror distan de ser imaginarios. En la crítica hispanoamericana, Flora Botton Burlá relega los temas y motivos fantásticos a un segundo plano. Cualquier tema puede convertirse en fantástico si es capaz de producir juegos narrativos con el tiempo, el espacio, la personalidad y la materia (Botton Burlá, 1983: 195), de transgredir el orden real de las cosas. 
ría de Todorov, la caracterización de un cuento multifacético como "El calamar opta por su tinta" como fantástico.

De la misma manera, muchos cuentos de Julio Cortázar deberían eliminarse de la categoría "fantástico" si aplicáramos el criterio principal de Todorov. Ilustro de nuevo con un ejemplo canónico: "Las Ménades" incluido en Final del juego. Sin embargo, para un análisis adecuado del relato se vuelve necesaria una breve digresión sobre la explicación psicoanalítica de lo fantástico.

\section{IV}

Sigmund Freud, en su análisis de 1919 de "El hombre de la arena" de Hoffmann, aporta das Unheimliche a las discusiones alrededor de la literatura fantástica. Sabemos que no hay traducción exacta para el término. Se propuso "lo siniestro", "lo extraño" y "lo ominoso", pero la historia de la palabra alemana impide una adaptación adecuada a otro idioma. Freud reproduce una etimología detallada de unheimlich y la compara con términos parecidos en varias lenguas modernas y antiguas (1919: 220ss). Resultado: no hay correspondiente exacto...

Prescindo de las especulaciones psicoanalíticas del médico vienés, me limito a indagar en las posibilidades del término unheimlich para la crítica literaria. ${ }^{24}$ Define Freud, después de una larga serie de acercamientos a la palabra citados de diferentes diccionarios: ${ }^{25}$ "Entonces, heimlich es una palabra que ha desarrollado su significado siguiendo una ambivalencia hasta coincidir al fin con su

${ }^{24}$ Si Freud "usó" la literatura como herramienta para comprobar la validez de sus teorías psicológicas, ¿por qué no usar a Freud como auxiliar del análisis literario?

${ }^{25}$ Freud da especial importancia a una definición de Schelling según la cual unheimlich es todo lo secreto, lo que debería permanecer escondido, pero salió a la luz (1919: 225). 
opuesto, unheimlich. De algún modo, unheimlich es una variedad de heimlich" (1919: 226).

Quizás el uso actual de la palabra sirva para explicar esta hermosa deconstrucción freudiana. Heimlich puede ser una persona que ubica el centro de su vida en su propia casa. Heimlich pueden ser una situación y un entorno agradables y acogedores, pero heimlich también puede asignar una acción llevada a cabo a escondidas y ubicada en la zona gris entre lo permitido y lo prohibido. La sílaba "un" tiene valor de negación. Unheimlich debería ser lo contrario de heimlich. Sin embargo, heimlich tiene por lo menos dos acepciones entre sí contrarias. Unheimlich, entonces, niega una acepción y afirma, al mismo tiempo, la otra. ${ }^{26}$

El "temor cósmico", los miedos experimentados por los protagonistas de "El calamar opta por su tinta" son sentimientos unheimlich. Vivirlos conscientemente significaría renunciar a la protección del hogar ("Heim"), al mismo tiempo sólo se pueden experimentar plenamente en la intimidad, de manera clandestina, en el hogar ("Heim"), son propiamente dicho incomunicables. Es más: desde la intimidad del hogar estas angustias unheimlich amenazan con la destrucción del hogar, con su conversión en no-hogar que expondría a sus habitantes a una existencia con plena conciencia y en medio de lo unheimlich que, de esta manera, se convertiría en su hogar.

Sin embargo, Hélène Cixous, en un ensayo canónico sobre das Unheimliche, es incapaz de ver las posibilidades críticas del concepto. Lo usa, al contrario, para psicoanalizar a Freud. El diccionario del médico vienés, apunta Cixous, sus variados intentos de definir y traducir unheimlich engañan al lector, y hasta al autor, porque apenas ellos vuelven unheimlich el término, es decir: el lenguaje

${ }^{26}$ Todorov podría aprovechar lo vacilante del término para sus propias tesis acerca de la vaguedad de lo fantástico, mas en su Introducción... sólo rechaza el uso del término como mera hipótesis en los escritos del psicoanalista (1979: 41). 
nos aleja de la realidad (1976: 530). Hay que agregar: no el lenguaje, sino la exégesis de Cixous nos aleja de la realidad. La etimología de unheimlich presentada por Freud es fáctica, los significados contradictorios de la palabra existen y se emplean en el alemán cotidiano hasta hoy. Puede que las conclusiones psicológicas de Freud sean arbitrarias, mas en grado mucho más alto lo son las de Cixous. La psicoanalista incluso afirma que Freud envidia la creatividad del escritor (538) y que percibe a Hoffmann como doble que lo incita a la producción de ficción artística (540). ${ }^{27}$ A final de cuentas, el análisis de Cixous reduce el estudio de Freud a una mera aventura lingüística que revela el poder auto-creativo de la escritura: "Basically' Freud's adventure in this text is consecrated to the very paradox of the writing which stretches its signs in order to 'manifest' the secret art it 'contains"' (547). ${ }^{28}$ Se trata de una interpretación que emplea el mismo procedimiento que Freud usa ante la narración de Hoffmann: un texto literario-ficticio funge como documento que permite el psicoanálisis de su autor o de un grupo de autores que manifiestan en sus obras tendencias similares. Sin embargo, Cixous tiene que forzar aún más su análisis, dado que

${ }^{27}$ Es muy probable que Cixous se base para estas afirmaciones en la famosa carta de Freud a Arthur Schnitzler del 14 de mayo de 1922. En ella, Freud apostrofa al novelista y dramaturgo austriaco efectivamente como doble y expresa su envidia ante la efectividad superior del literato en comparación con la del médico. No obstante, Freud se dirige a Schnitzler porque éste trabaja precisamente los temas puestos en moda por el psicoanálisis: lo onírico, la sexualidad reprimida, el mundo de las posibilidades. No es lícito deducir de ello un deseo reprimido de Freud de ser escritor. La carta se encuentra en http://www.zum.de/Faecher/D/ BW/gym/Novellen/schnitzler/freud.htm.

${ }^{28}$ Llama la atención el uso de las comillas en esta cita. David Stove, en Scientific Irrationalism. Origins of a Postmodern Cult (2007), demostró de manera convincente que este uso en la epistemología del siglo XX (Popper, Kuhn, Feyerabend, Lakatos) sirve sobre todo para vaciar las palabras de sus contenidos. En nuestro caso "basically", "manifest" y "contain" podrían significar igualmente sus opuestos y, de esta manera, no significar nada. 
necesita reinterpretar el estudio psicológico de Freud como texto literario, como "a strange theoretical novel" (525). No cabe duda de que este tipo de exégesis anula las capacidades explicativas del término "unheimlich". De hecho, aunque Cixous afirma que lo "unheimlich" se convierte en miedo, reduce al mismo tiempo este miedo al temor ante la posible pérdida de un órgano, es decir: miedo a la castración. La utilidad del término para la comprensión de literatura fantástica se transforma con esto en mínima. Procuro demostrar con mi breve análisis de "Las Ménades" que lo "unheimlich" sí puede ser aplicado de manera productiva en el análisis de un cuento fantástico, sobre todo si se utiliza junto con los componentes básicos propuestos en mi artículo: miedo y narración mimética.

\section{V}

No puede haber vacilación en el lector de "Las Ménades". El título del cuento prefigura su recepción. El lector implícito no puede dudar acerca de lo verídico de lo narrado: un director de orquesta provoca con su arte tal entusiasmo en el público que finalmente se convierte en la causa de su muerte. El público lo destroza, probablemente lo devora. Cortázar adapta un mito antiguo: la muerte de Orfeo, su destrucción por las Ménades, un grupo de mujeres que originalmente crió a Dionisio para posteriormente convertirse en sus más fieles seguidoras. El juego intertextual se percibe incluso en los detalles: Dionisio, Homero, las Furias, las Bacantes hallan sus representaciones modernas en el cuento de Cortázar. Repito: el título guía la lectura. Si el narrador argentino hubiera escogido otro título, sí podría haber vacilación en el lector. Aunque varía de lector en lector, los hechos narrados serían, por lo menos durante cierto tiempo, inexplicables y sospechosos. En un artículo de 1979, precisamente Tzvetan Todorov insiste en la importancia de 
los pre-textos literarios. Según el crítico, toda la literatura es endogénesis, es decir: los textos se originan en y por otros textos. Y texto es el título, es la biografía del autor, es su entorno social e histórico. No hay componentes que justifiquen la afirmación de la exogénesis de la producción literaria: "But if bio-graphy, socio-graphy, picto-graphy are all 'interior' to the work, what remains to exogenesis? Nothing. The notion of endogenesis immediately loses its reason for being and becomes a synonym for genesis alone" (Todorov, 1979: 227). Es muy probable que el lector de "Las Ménades" conozca el texto del que surge el cuento argentino, su hipotexto según la terminología propuesta por Gérard Genette. Por ende, no hay ni sorpresa ni el momento de vacilación que genera lo fantástico en la teoría de Todorov de 1970. Sí hay, por otro lado, un juego muy marcado con la polivalencia del adjetivo "unheimlich". El Maestro debe percibir el conjunto formado por orquesta, sala y público como lo más familiar y seguro de su existencia, como su "Heim". Esta impresión se refuerza por un comentario de la señora de Jonatán antes del inicio del concierto: "—Ahí tiene, ahí tiene a un hombre que ha conseguido lo que pocos. No sólo ha formado una orquesta sino un público" (Cortázar, 2008: 55). El Maestro está literalmente en su ambiente: lo cree conocer porque él lo ha creado. Sin embargo, el entusiasmo orgiástico y el fanatismo del público (guiado por el grupo de las Ménades) convierte este hogar en una pesadilla: lo "heimlich" se transforma en "unheimlich". Finalmente lo "unheimlich" se interioriza mediante la muerte del Maestro y, de esta manera, se reconvierte en lo "heimlich", dado que, según el psicoanálisis freudiano, no puede haber lugar más "heimlich" que la muerte que, no obstante, se nos suele presentar como lo más "unheimlich". ${ }^{29}$

${ }^{29}$ Renuncio a una traducción de los términos "heimlich" y "unheimlich" que sólo podría entorpecer el análisis. 
El narrador de estos acontecimientos violentos es un testigo ocular quien, además, conoce a varios de los involucrados personalmente. Es decir: un narrador fiable cuyo propósito principal es reproducir los hechos tal cual, un narrador mimético. Este narrador entra a un espacio que no es suyo, se percibe a sí mismo como ajeno en el ambiente del concierto, no sólo ajeno a los actos violentos, sino también al entusiasmo musical provinciano del público. De este modo, el narrador representa al mismo tiempo la función del lector implícito. Los hechos observados y reproducidos generan el miedo ontológico, las dudas y frustraciones ante actos inexplicables (en este caso actos míticos y vagamente telúrico-primitivos), en él y, a la vez, en el lector. Lo "heimlich" y lo "unheimlich" son catalizadores en este contexto, impulsan el conflicto, pero también pretenden describir y caracterizar el miedo que amenaza a narrador y lector.

No cabe duda de que "Las Ménades" puede ser clasificado como literatura fantástica, a pesar de que no exista momento de vacilación en el lector. En primer grado, la actitud mimética del narrador, el carácter del miedo reproducido y transmitido al lector; en segundo grado, el juego intertextual con el mito de Orfeo, así como las alusiones indirectas a lo "unheimlich" freudiano justifican su ingreso al canon de lo fantástico.

\section{VII}

No me propuse con estas observaciones formular una nueva teoría de lo fantástico, encontrar una nueva definición del género literatura fantástica, tampoco invalidar clasificaciones como realismo mágico o lo real maravilloso. Sólo propongo repensar el canon de lo fantástico con base en criterios sencillos. Sobre todo se volvió necesario oponerse a lo dogmático de la teoría de Tzvetan Todorov, dogmatismo que el autor de la Introducción a la literatura fantástica 
rechazó, pero que muchos de sus seguidores han introducido en crítica y teoría del género fantástico. Por otro lado, es igualmente necesario oponerse a un relativismo crítico que sencillamente rehúye los intentos de formular y defender teorías y definiciones.

Mi navaja de Occam la proporcionan Franz Roh y H. P. Lovecraft. Mediante ellos el principal elemento definitorio de la literatura fantástica podría reducirse a la fórmula: miedo ontológico transmitido al lector por procedimientos miméticos tradicionales, pero readaptados en contextos narrativos innovadores. Apliqué esta fórmula - y una breve digresión a lo "unheimlich" de Sigmund Freud - a dos cuentos antológicos de la literatura fantástica que, no obstante, deberían excluirse como objetos de estudio si aplicáramos los criterios de Todorov, sobre todo su elemento clave: la vacilación ante los hechos narrativos. Sin embargo, muchas otras herramientas analíticas podrían encontrarse —en la producción de literatura fantástica o en las numerosas teorías elaboradas a su alrededor - que permitirían el diálogo interminable entre teorías que siempre serán falseadas, el diálogo en medio del "tercer mundo” científico ideado por Karl Popper que podría acercar también nuestras materias a la cientificidad. ${ }^{30}$

\section{Fuentes}

Abraham, Carlos, 2006, Estudios sobre literatura fantástica, Buenos Aires, Quadrata.

Alazraki, Jaime, 1967, "Borges y el problema del estilo", Revista Hispánica Moderna, núm. 3/4, año 33, pp. 204-215.

, 1984, "El texto como palimpsesto: Lectura intertextual de Borges”, Hispanic Review, vol. 52, núm. 3, pp. 281-302.

${ }^{30}$ Remito al capítulo 3, "Epistemología sin sujeto cognoscente", de Conocimiento objetivo (1974), y a muchos pasajes más en éste y otros libros del filósofo. 
Bioy Casares, Adolfo, 1999, "El calamar opta por su tinta”, en Historias fantásticas, Madrid, Alianza / Emecé, pp. 211-225.

, 2008, "Prólogo", en Antología de la literatura fantástica, Jorge Luis Borges, Adolfo Bioy Casares, Silvina Ocampo (eds.), Buenos Aires, Debolsillo.

Botton Burlá, Flora, 1983, Los juegos fantásticos, México, UNAM.

Calderón Bird, Raúl, 2002, La narrativa y el teatro fantásticos de Elena Garro, tesis de doctorado no publicada, México, UNAM.

Carpentier, Alejo, 1975, "Confesiones sencillas de un escritor barroco" (entrevista con César Leante), en Recopilación de textos sobre Alejo Carpentier, Salvador Arías (ed.), La Habana, Casa de las Américas, pp. 57-71.

, 1987, "Prólogo", en Obras completas II. El reino de este mundo, Los pasos perdidos, México, Siglo XXI , pp. 11-19.

Chiampi, Irlemar, 1983, El realismo maravilloso. Forma e ideología en la novela hispanoamericana, Caracas, Monte Ávila.

Cixous, Hélène, 1976, "Fiction and Its Phantoms: A Reading of Freud's Das Unheimliche (The 'Uncanny')", New Literary History, Robert Dennomé (trad.), vol. 7, núm. 3, pp. 525-548.

Cortázar, Julio, 2008, “Las Ménades”, en Final del juego, México, Punto de lectura, pp. 53-73.

D’Ors, Eugenio, 1964, Lo barroco, Madrid, Aguilar.

Freud, Sigmund, 1976, Lo ominoso, en Obras completas 17, James Strachey, Anna Freud (eds.), José L. Etcheverry (trad.), Buenos Aires, Amorrortu editores.

Hahn, Oscar, 1978, El cuento fantástico hispanoamericano en el siglo XIX, México, Premia Editora.

Lovecraft, H. P, 1995, El horror sobrenatural en la literatura, Melitón Bustamante (trad.), México, Fontamara. 
Llarena, Alicia, 1997, "Un balance crítico: la polémica del realismo mágico y lo real maravilloso americano (1955-1993)", en Anales de Literatura Hispanoamericana, vol. 26, núm. I, Madrid, UCM.

Menton, Seymour, 1993, La nueva novela histórica de la América Latina 1979-1992, México, FCE.

, 1998, Historia verdadera del realismo mágico, México, FCE.

Morales Benito, Lidia, 2011, "La búsqueda de una nueva verosimilitud. Literatura neofantástica y patafísica”, Carnets III. L'(In)vraisemblable, enero, pp. 131-146.

Ong, Walter J., 2002, Orality and Literacy, Londres y Nueva York, Routledge.

Pardo Fernández, Rodrigo, 2009, "La ficción y la literatura fantástica, ese oscuro recinto interminable", en De la ficción o de por qué llamar a las cosas por su nombre, Granada, Diputación de Granada, pp. 9-39.

Parkinson Zamora, Luis, 1998, "Hacia Alazraki”, Revista Hispánica Moderna, núm. 1, año 51, pp. 178-182.

Popper, Karl, 1967, Conjeturas y refutaciones. El desarrollo del conocimiento cientifico, Néstor Míguez (trad.), Barcelona, Paidós.

, 1974, Conocimiento objetivo, Carlos Solís Santos (trad.), Madrid, Tecnos.

, 1977, Búsqueda sin término. Una autobiografía intelectual, Carmen García Trevijano (trad.), Madrid, Tecnos.

Rall, Dietrich (comp.), 2008, En busca del texto. Teoría de la recepción literaria, México, UNAM.

Roh, Franz, 1925, Nach-Expressionismus. Magischer Realismos, Lepzig, Klinkhardt \& Biermann.

Steinmetz, Jean-Luc, 1990, La littérature fantastique, París, Presses Universitaires de France. 
Stove, David, 2007, Scientific Irrationalism. Origins of a Postmodern Cult, New Brunswick y Londres, Transaction Publishers.

Todorov, Tzvetan, 1979, "On Literary Genesis", Yale French Studies, Ellen Burt (trad.), núm. 58, pp. 213-235.

, 1994, Introducción a la literatura fantástica, Silvia Delpy (trad.), México, Ediciones Coyoacán.

Vargas Llosa, Mario, 2008, "El viaje a la ficción", Letras Libres, núm. 110, febrero, pp. 12-18.

Vax, Louis, 1960, L'art et la littérature fantastique, Presses Universitaires de France, París.

Yushimito del Valle, Carlos, 2009, "Pierre Menard, autor de Cortázar. Aproximaciones a lo neofantástico en 'Casa tomada' y "Carta a una señorita en París”, Espéculo. Revista de estudios literarios, núm. 41, disponible en: http://www.ucm.es/info/especulo/numero41/menacor.html, (consultado el 8/VI/2011).

(Artículo recibido el 5 de marzo de 2014; aceptado el 12 de mayo de 2014) 